\title{
Conceptual design of collaborative virtual environments for education using a theater-based metaphor
}

\author{
Alberto Bucciero*, Anna Lisa Guido, Luca Mainetti \\ GSA Lab, Department of Innovation Engineering, University of Salento, Via Monteroni, Lecce, Italy
}

\section{Abstract}

Collaborative Virtual Environments (CVEs) are becoming more and more important in many areas because they offer users the opportunity to experiment with novel interaction paradigms in order to perform collaborative work or have engaging experiences 'being together'. One of the most promising application fields is eLearning, where CVEs give the unique opportunity to explore effective educational formats. Surprisingly, if compared with other more traditional fields as software engineering and database, we note a lack of design approaches. We point out that a well-founded design approach is crucial to develop collaborative experiences that could generate substantial and measurable educational benefits. To meet this challenge, in this paper we present a set of founding concepts that enable pedagogs and teachers designing effective 3D virtual worlds for education. To keep our concepts simply understandable, we based our design method on a widespread metaphor: the theater. We demonstrate through a real case study the promising advantages of our approach: expressiveness to capture collaborative features at a high level of abstraction, semi-formality to facilitate the establishment of a common ground between educational designers and CVEs engineers, and guidance to enable non-experts to cope with all the relevant aspects of a $3 \mathrm{D}$ virtual world.

Keywords: collaborative virtual environment, conceptual design, conceptual map, design metaphor, multi-user virtual environment, $3 \mathrm{D}$ virtual world

Received on 3 March 2011; accepted on 1 May 2011

Copyright ( $\odot 2011$ Bucciero et al., licensed to ICST. This is an open access article distributed under the terms of the Creative Commons Attribution licence (http://creativecommons.org/licences/by/3.0/), which permits unlimited use, distribution and reproduction in any medium so long as the original work is properly cited.

doi: 10.4108/icst.trans.eeel.2011.e3

\section{Introduction}

Collaborative Virtual Environments (CVEs) are computer-based 3D virtual worlds where users can meet and interact with each other in order to perform effectively collaborative work or have engaging experiences 'being together' [1]. As we move to a networked virtual world, with the promise of improved data-flow through broadband networks [2], also due to the popularity of Second Life [3], CVEs, Multi-User Virtual Environments, and $3 \mathrm{D}$ Virtual Worlds, are becoming more and more important in many areas, such as eLearning [4], eEntertainment [5], eMarketing [6], cultural heritage [7], and eMeeting $[8]$.

*Corresponding author. Email: alberto.bucciero@unisalento.it
One of the major fields for shared virtual worlds is eLearning, where CVEs give support for innovative pedagogical paradigms and they enable teachers exploring effective educational formats [9]. Researchers [10-13] '... have proven the effectiveness of collaborative online learning if compared to other educational practices (e.g. competitive or personalized learning)'. Also, researchers [13] '... demonstrate that collaborative activities, focused on a cognitive goal and supported by experts, result in the more meaningful and efficient acquisition of knowledge'.

Due to their internal complexity and behavior, the design of 3D virtual worlds for education traditionally has been the privilege of engineers. Instead, as other authors observe [14], to provide valuable learning experience through CVEs pedagogical, educational, 
and technical skills correctly combined, without confining pedagogs and educators only to learning objects design [15]. Technology must be designed around the learning experience, and not the other way around, if we want to correctly answer to educational needs.

Surprisingly, if compared with other more traditional fields as, for example, web engineering, requirements engineering, software engineering, and database, we note a lack of design approaches that can meet together the needs of the several skills involved in the production of an eLearning collaborative experience.

We point out that a well-founded design approach is crucial to develop 3D virtual worlds that could generate (beside fun and engagement) substantial and measurable educational benefits. We advocate for an establishment of a common ground between educational designers and CVEs engineers.

This issue came to be discussed also in scientific communities: authors in [16] face the problem '... to facilitate educational designers and developers by providing a point of reference for making decisions on how to incorporate 3D environments into the applications they develop as well as for extending their capabilities by integrating more functionality'. In this research work some design principles are explained both from the technological and from the educational points of view. The abovementioned design principles are the expression of the difficulty to design CVEs for eLearning without a clear guideline, highlighting the immaturity of design methodologies in this field: that is a clear motivation to our research.

To meet the challenge, in this paper we present a set of founding concepts that enable pedagogs, teachers, and tutors designing effective 3D virtual worlds for education, and discussing with engineers for implementation. We derived our conceptual approach abstracting recurring situations we encountered in developing CVEs for eLearning. As reader can see in [17], from 2004 as technical partners we collaborated with the HOC-Lab of Politecnico di Milano (Italy) deploying several 3D virtual worlds in real schools, reaching more than 9000 students and their teachers from Europe and USA. Continuously evolving the technology, we re-purposed the CVEs adapting them to different educational experiences. In fact, in 2004 we started with Learning@Europe (L@E) project [18], where the subject was the European history; then, we developed the Stori@Lombardia (S@L) environment [19], dealing with the medieval history; finally, we deployed the Learning@SocialSport (L@SS) 3D virtual world [20], moving the educational subject to the ethical and social issues of sport.

The frequent change of the educational format among the above-mentioned projects gave us the possibility to discuss more and more with educational designers and developers, deriving a map of concepts that links together these different skills; this let us to define a common layer for the conceptual design of CVEs, without requiring specific technical competencies for the designer.

To make the model more understandable we decided to convert all technical elements, proper of the 3D CVEs (i.e. 'avatar', 'gate', '3D space', etc.), in common concepts. To keep simple and sound the design primitives, we based our conceptual approach on a widespread metaphor: the theater. Using model elements as 'actor', 'curtain', 'stage', etc., educational designers can provide engineers with precise requirements of 3D CVEs (for the implementation), describing both the static and the dynamic points of view. The chosen metaphor allows designers to describe the CVE as a set of acts of a scene that take place in a theater where several actors play a role following a predefined storyboard.

The paper is organized as follows. Section 2 reports on key related work in the area of CVEs for eLearning and in CVEs modeling approaches. Section 3 frames the CVEs conceptual design (open) problem, illustrates our methodological approach, and sketches early solutions to address the design issues. Section 4 presents an articulated case study that exploits the design method and demonstrates the promising advantages. In Section 5, the conclusions summarize our key messages and sketch future research directions.

\section{Related work}

CVEs have rapidly grown in interest and diffusion also thanks to the popularity of the Second Life platform. Actually, CVEs are exploited in many domains as eLearning, eEntertainment, eMarketing, cultural heritage, and eMeeting. In particular for eLearning we can observe heterogeneous examples of application. In Barab's Quest Atlantis virtual world [21] students play answering quests to save their land from an imaginary disaster. In Dede's River City [22] high school students populate a virtual town of the 19th century trying to investigate about the causes of an epidemic. In these projects the educational aims, even if present, are not clearly focused, so users can acquire knowledge but without following a precise learning goal.

Other examples of eLearning-oriented CVEs-specialized as Web-based Educational Virtual Environments (EVEs) and Web3D EVEs-are CVE-VM [23], DeskTOP [24], DigitalEE [25], Viras [26], and NICE [27].

Differently to these approaches of 'informal education', there are only few attempts where the virtual experience of users is designed with a clear learning aim. Whyville [28] is a virtual world where teenagers attend to weekly lessons on a broad range of topics, from science and business to art and geography, exploring the 'learning by doing' educational paradigm. Scuola 3D [29] is an Italian learning community hosted in a $3 \mathrm{D}$ virtual environment. It involves several actors having different skills (pedagogs, educators, teachers, tutors, learners, public 
administrators). The Scuola 3D virtual world is based on the ActiveWorlds platform [30].

Even if CVEs are widespread, the problem of their conceptual design is far to be solved. The traditional virtual environment design techniques are based on real-world concepts and the usual approach is to design just the real situation, translating physical concepts in a $3 \mathrm{D}$ virtual world. For example, Collaborative Virtual Real Environment (CVRE) [31] provides a modeling facility using everyday life entities such as rooms, auditorium, and so on. The model allows defining people, space, tools, and rules: people interact in the virtual place using available tools as chats and blogs. Every user has an assigned role that defines his/her capabilities; for example, an office manager will be responsible only in his/her office and he/she will be a generic user in other spaces. CVRE design concepts do not follow any predefined metaphor.

A completely different approach to conceptual design, which can be used to model 3D virtual worlds, is the Process Modeling Language (PML) [32]. PML is a notation derived from UML that provides two model views: (i) the High Level UML-Based Diagram (where P-activity is used to design actions and P-class to design objects) and (ii) the Low Level Process Language, an objectoriented language that provides a representation of the classes defined in the P-class using methods defined in the P-activity. The output of the Low Level Process Language may be used in the graphical engine to create the 3D environment. The PML approach, if compared to CVRE, is more formal and does not make use of the real-world metaphor; this leads to a weak expressivity of the notation that is more oriented to the software engineering area.

NiMMiT (Notation for Modeling Multimodal Interaction Techniques) $[33,34]$ is an approach to design the human-computer interaction. It is based on a graphical notation oriented to virtual environments. NiMMiT uses the concepts of state and events: a state reacts to a set of events that activate a task (or a set of tasks) and allow evolving the current state in the next state of the application. NiMMiT provides an authoring tool that enables designers to export the model in a XML format, which can be used as input for an engine in order to automatically generate the wanted virtual environment. The statechart metaphor is not too technical, so it can be used also by non-experts, but do not contain any particular semantics to help designers during modeling.

InTML (Interaction Techniques Markup Language) [35] is a domain-specific language defined to describe several aspects of a virtual environment (devices, objects, interactions, etc.). InTML uses a dataflow paradigm where objects and devices are part of the flow and they are linked each other. A 'filter' object allows representing the interaction that, in its simple form, is made up of a set of inputs and outputs. Designers may define and customize filters. Each filter may use other filters to send its output. As for
NiMMiT, InTML allows exporting a model in XML format to feed an engine; while, its graphical notation is more rigid and its semantics more obscure to non-experts.

Whereas these approaches provide technical designers (mainly engineers) with support for modeling the graphical or behavioral aspects of $3 \mathrm{D}$ virtual worlds, they lack in characterizing the semantics of the user interaction and collaboration in CVEs.

To meet this challenge, we propose to extend the semantic perspective to establish a common ground between designers of educational experiences and CVEs engineers, and to provide guidance (in the form of a step-by-step wizard configuration software) to enable non-experts to cope with all the relevant aspects of $3 \mathrm{D}$ virtual worlds. This perspective is only partially covered by existing works (NiMMiT and InTML in particular).

In the next section we frame the CVE design problem in its complexity dimensions.

\section{CVE conceptual design}

\subsection{The CVE design problem}

As the section on related work demonstrates, the modeling of CVEs has been faced mainly from a physical (CVRE) or a logical perspective (PML, NiMMiT, and InTML), exposing the designer to some level of technical details typical of the 3D CVEs. If we want to enable directly domain experts to model CVEs (pedagogs, educators, and teachers for the learning domain), we have to reduce the number of elements the designer must keep under control, focusing on those that are related to the goal of the collaboration and social interaction. In other words, it is needed to add the conceptual perspective to CVE design.

The internal complexity and behavior of CVEs cross a number of dimensions that characterize virtual spaces:

- The graphic appearance of the environment and the corresponding semantics conveyed to the user.

- The spatial organization of the world that determines user activities (people act, more or less, where they are).

- The user representation that influences the sense of being together.

- The reactive objects in the world, which enable interactions between users and the environment.

- The rules that define how actions in the world can evolve and shape collaboration among participants.

Blended learning and eLearning domains add other complexity dimensions to the design of CVEs. Authors in [16] summarize these needs in eight principles:

(i) Design to support multiple collaborative learning scenarios. 
(ii) Design to maximize the flexibility within a virtual space.

(iii) Augmenting user's representation and awareness.

(iv) Design to reduce the amount of extraneous load of the users.

(v) Design a media-learning centric virtual space.

(vi) Ergonomic design of a virtual place accessible by a large audience.

(vii) Design an inclusive, open, and user-centered virtual place.

(viii) Design a place for many people with different roles.

In particular, Principles 1,4 , and 5 are peculiar of the educational domain.

A correct approach to the conceptual design of CVEs for education must orchestrate all the above-mentioned elements guiding the designer to configure effective learning experiences. But lessons learned by researchers [35-37] designing valuable multi-user virtual environments for education must be taken into account:

- Lesson number 1: technology does not provide educational benefits directly, but as a component of an overall educational experience.

- Lesson number 2: the role of technology, in making the educational experience effective, is crucial but sometimes hard to understand, and more complex than it may look at first sight.

- Lesson number 3: the design of a complex, technology-enhanced educational experience is a complex activity following unusual rules.

- Lesson number 4 (consequence of Lesson 3): the design of a multi-user virtual environment to support an educational experience is a complex activity following unusual rules.

In the rest of the section we illustrate our solution following three main steps:

- Definition of a map of relevant concepts for CVEs.

- Characterization of their semantics applying the theatre metaphor.

- Re-definition of the conceptual map using terms related to the chosen metaphor.

\subsection{Our proposed solution to CVE conceptual design}

Map of concepts. Evolving our virtual world engine WebTalk [17] for educational experiences during the past six years-in collaboration with the HOC-Lab of
Politecnico di Milano under the L@E, S@L, L@SS, and L4A (Learning for All) projects-we faced a number of issues trying to make our technology highly configurable. To rise in generality, we have been driven by the need to capture all the relevant abstractions embodied in CVEs for education. These would have been a clear guideline to design the software architecture. The abstraction process has been the result of several iterations that involved on the one hand technical experts and on the other hand conceptual modeling and domain experts in analyzing CVEs and 3D virtual worlds for education (but also for other fields).

The result is summarized in the 'concept map' presented in Figure 1. The concept map [38] is a diagram showing the relationships among CVE (recurring) concepts. In Figure 1 concepts are represented as nodes, while relationships are symbolized as labeled arrows. Labels express the informal semantics of relationships.

As readers can see, we identified two different sets of concepts: static concepts (white nodes) and dynamic concepts (dark nodes). They capture in a separate way two aspects of CVEs: (i) the world appearance and its spatial organization, (ii) the interaction among users and between user and the world. The two concerns lead to two model views: (i) static view and (ii) dynamic view (see Paragraph 3.2.2).

Taking a careful look at the concept map, readers can observe the presence of some fundamental concepts in CVE design, that are described in the following.

People have a central role, because they are the protagonists of the virtual environment (i.e. they are leading actors of the educational experience); many other concepts are related to this one.

The Door is the entry point of the Spaces the virtual environment is composed of. When People access a Door, they must be identified; then, depending on their Roles, the environment configures itself consequently.

Moreover, a relationship between Doors and Privileges has been considered: the Door could change the Privilege that, in turn, is related to the People.

It is important to note the presence of a Supervisor for the specific virtual space. A Supervisor is a particular Person who acts as a guide or a tutor for other users during the virtual sessions. In other words a Supervisor is a staff member who makes sure that the action is moving along predefined lines, taking care of the educational experience goal.

The main focus of the dynamic concepts is to provide constructs to model the social interaction occurring during virtual sessions. To have measurable educational benefits the interactions among People must take place in a predefined time slot, according to a storyboard. Time slots (controlled quite precisely automatically or manually by the Temporary Supervisor, i.e. the guide, for the same time period) define the span when People can execute Actions governed by Rules. 


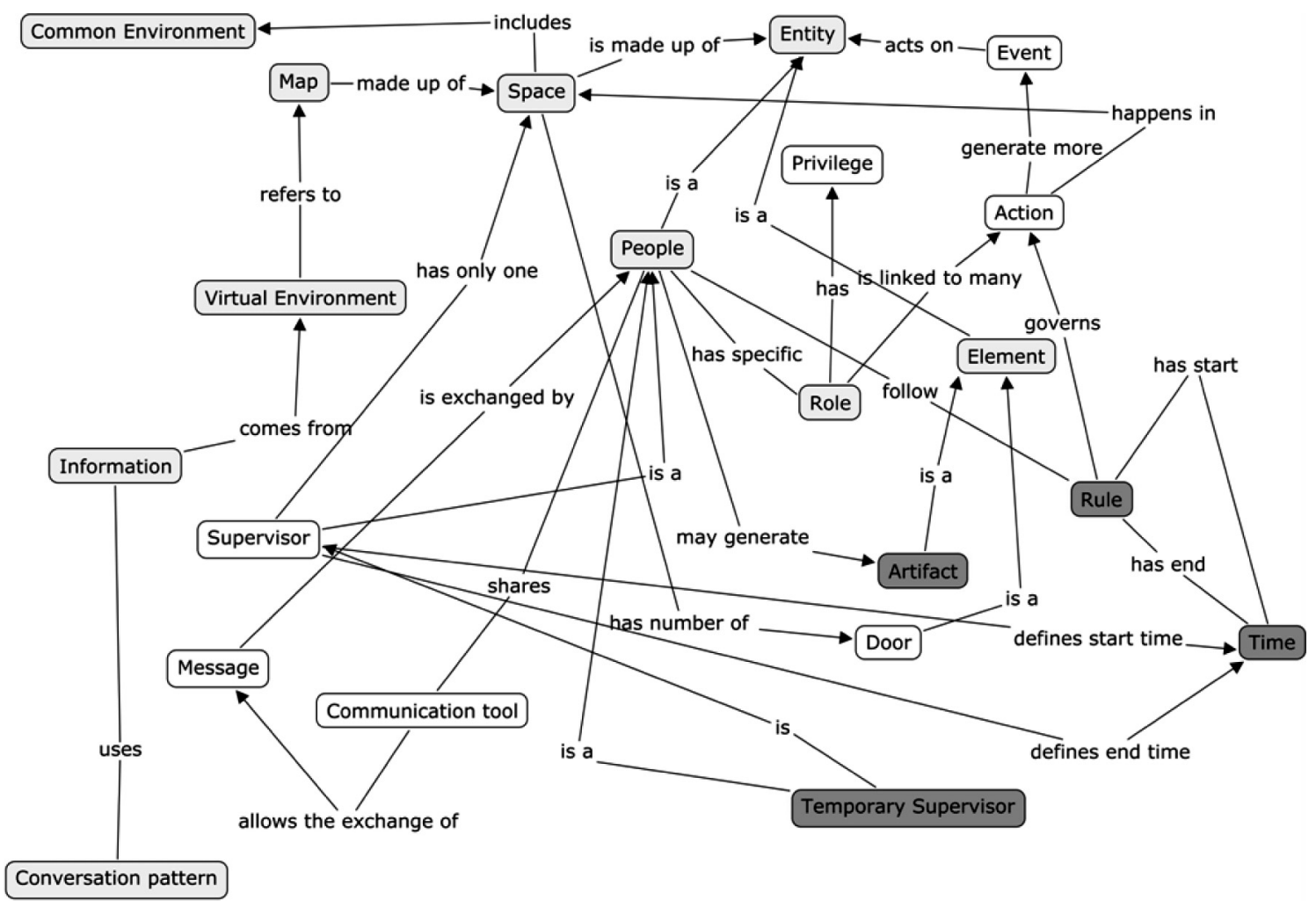

Figure 1. Map of CVE concepts.

An Action, raised by an Event, can act on Entities, which can be either People or world Elements.

The concepts of Information and Message are kept separate because of their different meanings: information models data coming from the virtual environment (as, for example, learning material, quizzes, etc.) and from here transferred to the People, while a Message represents unformatted data exchanged among People through Communication tools provided by the environment (i.e. Shared board, Chat, Voice, etc.).

Table 1 presents a complete list of both static and dynamic concepts. Furthermore, the next section provides readers with a description of the informal semantics. To keep the approach sound, each concept is mapped on abstractions belonging to the theater domain borrowing their distinctive semantics.

Design metaphor and design semantics. We carried out an experiment capturing the concepts that underlie the theatre domain and representing them with a concept map. The result (Figure 2) is surprisingly similar to the diagram shown in Figure 1: there is a strong analogy between the theater field and the CVE realm that applies to both static (white nodes in Figure 2) and dynamic concepts (dark nodes in Figure 2). The metaphor allows us to describe the virtual environment as a set of Acts of a Scene that take place in a Theater where the space (objects, lights, sounds) is organized according to a Scenography and Actors play a role following a Script (a written storyboard).
To facilitate the understanding of the analogy, in the following we provide readers with a definition of the more important concepts of the theater domain in connection with the CVE domain [39].

- Theater: a building (i.e. a finite space) where a performance takes place.

- Stage: a large platform on which actors can stand and can be seen by an audience.

- Scenography: a description of a stage that illustrates the environment organization in term of space, set, costume, sound, lighting, etc.

- Script: the written text of a stage play.

- Act: a segment of a performance of a theatrical work; it is an organizational part.

- Scene: a division of an act presenting continuous action in one place; it is the shortest autonomous (semantic) unit in the script.

- Actor: a theatrical performer, i.e. a person who interprets a dramatic character or personality.

- Director: a person who oversees and orchestrates the theater production usually with responsibility for action, lighting, music, and rehearsals.

- Scene director: a person who is responsible for the stage setup. He/she can modify the original configuration.

ICST Transactions on e-Education and e-Learning July-September 2011 | Volume 11 | Issues 7-9 | e3 
Table 1. Mapping between CVE concepts and theater concepts, and their informal semantics for modeling 3D virtual worlds for education.

\begin{tabular}{|c|c|c|}
\hline CVE concepts & Theater concepts & Informal semantics for educational CVEs \\
\hline Map & Theater & $\begin{array}{l}\text { The overall space ( } 3 \mathrm{D} \text { world) where the educational experience (that can be } \\
\text { composed of several sessions) takes place. }\end{array}$ \\
\hline Virtual environment & Screenplay & \\
\hline Common environment & Scenography & \\
\hline Space & Stage & $\begin{array}{l}\text { The specific space ( } 3 \mathrm{D} \text { room) of the overall environment where an educational } \\
\text { session takes place. }\end{array}$ \\
\hline Entity & Theater entity & $\begin{array}{l}\text { Abstraction of a tool/thing that users can see and/or interact with during the } \\
\text { educational session. }\end{array}$ \\
\hline People & Actor & $\begin{array}{l}\text { A visible (or invisible) user of the educational session. He/she can interact with the } \\
\text { environment and/or with other users during the session. }\end{array}$ \\
\hline Information & Voice over & Information sent from the virtual world to the users (e.g. a tip, a question, etc.). \\
\hline Privilege & Script & The user's privilege (what the user can do) during a session. \\
\hline Role & Role & The user's role during the educational session (guide, helper, learner, etc.). \\
\hline Event & Event & $\begin{array}{l}\text { An event triggered by the environment or by a user. The event can activate actions } \\
\text { (e.g. the session's guide can teleport all users to a specific space in order to have a } \\
\text { test). }\end{array}$ \\
\hline Element & Element & A visible or invisible physical object of the virtual world. \\
\hline Time & Time & $\begin{array}{l}\text { Allows defining the temporal schedule of each event according to the storyboard of } \\
\text { the educational session. }\end{array}$ \\
\hline Artifact & Artifact & Somewhat (raw data, learning content) produced during an educational session. \\
\hline Supervisor & Director & $\begin{array}{l}\text { The responsible Person of an educational experience. He/she oversees and } \\
\text { orchestrates its execution. }\end{array}$ \\
\hline Temporary supervisor & Scene director & $\begin{array}{l}\text { The responsible Person of an educational session (a part of an experience) for a } \\
\text { limited period of time. }\end{array}$ \\
\hline Door & Curtain & Entry point for a virtual space. It allows changing roles and privileges of users. \\
\hline Conversation pattern & Conversation pattern & $\begin{array}{l}\text { Communication pattern used by the virtual environment to provide information to } \\
\text { users. }\end{array}$ \\
\hline Message & Dialog & $\begin{array}{l}\text { Message exchanged among users. It can be a dialog if the virtual environment } \\
\text { supports video/voice channels. }\end{array}$ \\
\hline Execute & & The dynamic behavior (business logic) of an action. \\
\hline Action & & The (automatic or manual) action generated by an event. \\
\hline \multirow[t]{5}{*}{ Actor $($ role $=$ helper $)$} & Prompter & $\begin{array}{l}\text { A power user who assists other users by suggesting them actions taking care of the } \\
\text { educational goal of the session. }\end{array}$ \\
\hline & Stage whisper & $\begin{array}{l}\text { A loud whisper by a user that is audible to other users but is supposed not to be } \\
\text { heard by all users (for example, is audible only to a team of users). }\end{array}$ \\
\hline & Act & A segment of an educational experience; it is an organizational part. \\
\hline & Instruction & Instruction that users must follow in order to participate to a session. \\
\hline & Scene & $\begin{array}{l}\text { A division of an act presenting continuous action in one place (for example, an } \\
\text { educational game); it is the shortest autonomous semantic unit in the storyboard of } \\
\text { the experience. }\end{array}$ \\
\hline Communication tool & & $\begin{array}{l}\text { A tool or a channel used by users to exchange messages (e.g. chat, shared board, } \\
\text { voice, etc.). }\end{array}$ \\
\hline
\end{tabular}

- Prompter: a person who assists (one acting or reciting) by suggesting or saying the next words of something forgotten or imperfectly learned. He/she gives the actors the opening words of each phrase a few seconds early.

- Stage whisper: a loud whisper by an actor that is audible to the spectators but is supposed for dramatic effect not to be heard by one or more of the actors.

We completed the experiment mapping the CVE abstractions to theater concepts. The result is shown in Table 1: the first column of the table lists the entities of CVEs, the second column associates them to elements of the theater domain, and the third column provides their informal semantics, which is characterized exploiting the theater metaphor.

As readers can see, although the most part of concepts is directly mappable, the CVE field makes use of some typical abstractions of software systems (Rule execution, Action, Communication tool), which do not have correspondence in the theater realm; the other way round, the theater domain is richer in concepts for the scene description (Stage Whisper, Act, Instruction, Scene) that anyway we explored performing the case study (see next paragraph).

The modeling primitives are used by different authoring profiles, which are involved in distinct phases of the design process: 


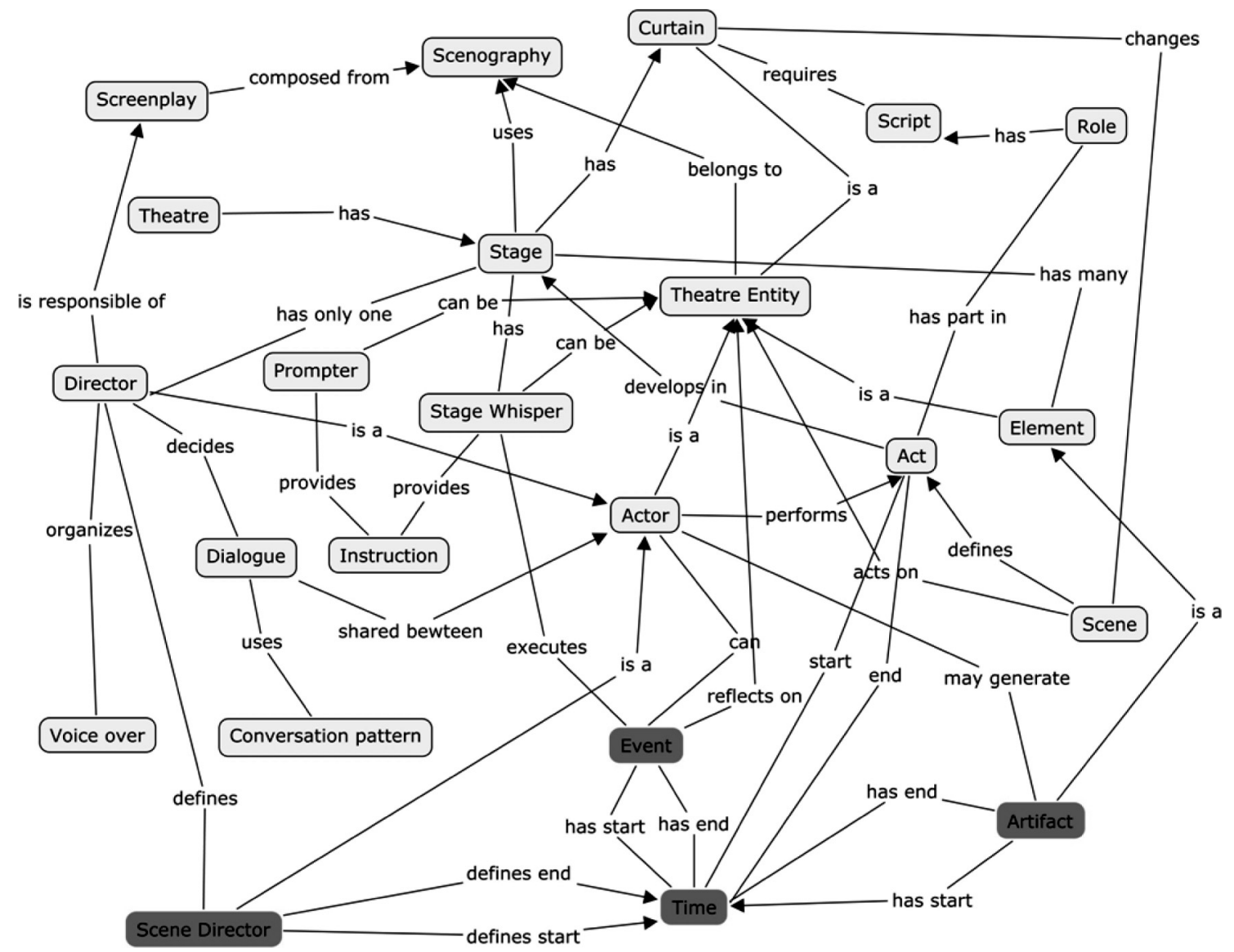

Figure 2. Map of theater concepts.

- Pedagog/Educational designer. He/she organizes the overall collaborative environment having as main objective the achievement of planned educational benefits. Therefore he/she must define the theater, the stages, the acts, the scenes, the involved actors, the collaboration artifacts and choreography etc., without providing their details (e.g. camera positions, lights, avatar speed, and so on).

- Teacher/Domain expert. He/she acts in a second phase configuring the environment and, more important, the educational contents to meet the characteristics of the users and the intent of the learning session (learning topic, class level, difficulty, learning time, etc.). $\mathrm{He} /$ she cooperates with the pedagog or the educational designer and in some cases they could be the same person.

- CVE engineer. If the deployment of a real 3D virtual world is needed, he/she has to add all technical features required to create the software artifacts that compose the environment (graphics, avatars, behaviors, etc.). He/she can achieve this goal configuring in strict sense a CVE engine (as we did), programming a CVE engine, or implementing a specific 3D virtual world. He/she starts working on the requirements provided by the pedagog/teacher using the theater metaphor concepts.

Two characteristics of our conceptual approach help designers during the modeling phases, offering a basic guidance: abstraction (the metaphor) and separation of concerns (model views). A static view describes all the entities that compose the virtual environment, whereas a dynamic view enables designers to specify the actions that modify the environment.

In the next section we present an articulated case study that exploits the propose design approach modeling a fragment of a real educational experience we did adopting a $3 \mathrm{D}$ virtual world.

\section{Case study and early results}

In this paper we summarize the results of the case study done to verify the effectiveness of the conceptual approach to the design of CVEs. We will start instantiating its concepts in order to describe a collaborative session in a 3D environment using the educational format of Learning@Europe. In the following we provide a short 
description of the educational format and the project organization.

\subsection{Educational format and experience organization}

The educational format of L@E is based upon a 7-week experience: students (high schools) intermix traditional study (with downloaded material) with 'on-line meetings', eForums, homework, etc. Four classes of different regions of Europe take part in the same experience with a cultural competition (2 against 2 ) among them: meeting other classes and the competition represent a strong motivation for being deeply involved.

The focal points of a L@E experience are the 'on-line meetings' ( 3 for each experience): students meet in a shared 3D virtual space, accessible via Internet. Each student ( 2 per each class), connected with the environment, is visualized (in the world itself) as an avatar. The environment-implemented with the WebTalk engine-provides innovative features fostering interaction (with the environment itself and the objects) and cooperation among students. In the virtual space, under the guidance of an 'educator' (the guide), students 'walk around' (Figure 3), find objects, interact, chat, 'fly', and play games (Figure 4). The virtual shared space provides a strong effect of 'presence' (there, together with the other students), which leads to engagement and psychological involvement.

'Manual skills' (required by games) and the interaction have been proven to be an effective motivation especially the context of a traditional school environment. Also games (e.g. 'treasure hunt'-see Figure 4, 'matching pairs', 'Olympic games', etc.) excite the attention, while, at the same time, they also require cultural preparation in order to be able to provide answers to questions and quizzes. The cultural competition has a double effect: it creates strong bonds among the students in the same team

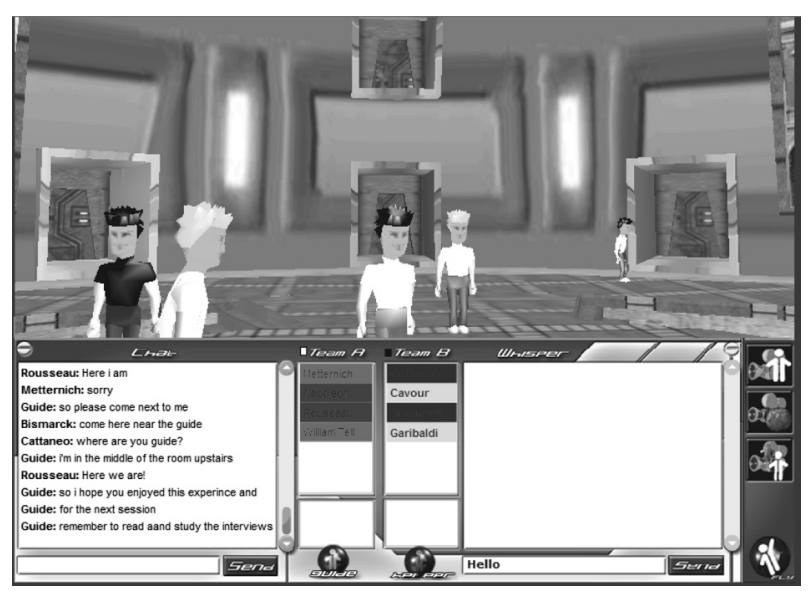

Figure 3. L@E City Domes.

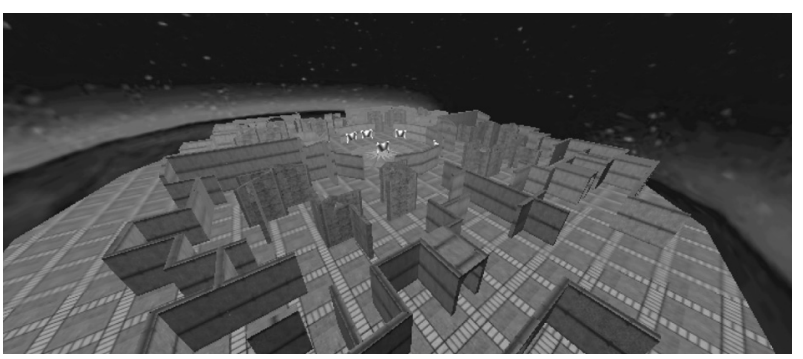

Figure 4. L@E Labyrinth of Treasure Hunt game.

and motivates (students and teachers) for excellence in the educational performance.

The four sessions (Figure 5) are structured in order to bring from a general knowledge of the formation of national identities in Europe, to a progressively more focused view of a specific cross-national aspect, which eventually students connect to their own local context and present culture.

Figure 5 shows a schema of the virtual educational experience's structure.

In Session 1 (Introduction), students meet each other and are introduced to the historical-cultural context of the theme they are going to deal with. They visit four city domes, one for each country involved that is 'decorated' with contents (images, descriptive text, objects) related to their country of origin. They are given a set of cultural materials, which will be discussed in Session 2. The detailed storyboard of the Session 1 is shown in Table 2.

In Session 2 (European History), students discuss about contents previously studied, related to the national history and identities of the countries involved; they also play cultural games related to the same contents. At the end of the session, they are assigned the second set of cultural materials on a specific European issue and the title of their homework, i.e. a research project in which they connect a relevant European subject to their local context and personal experience.

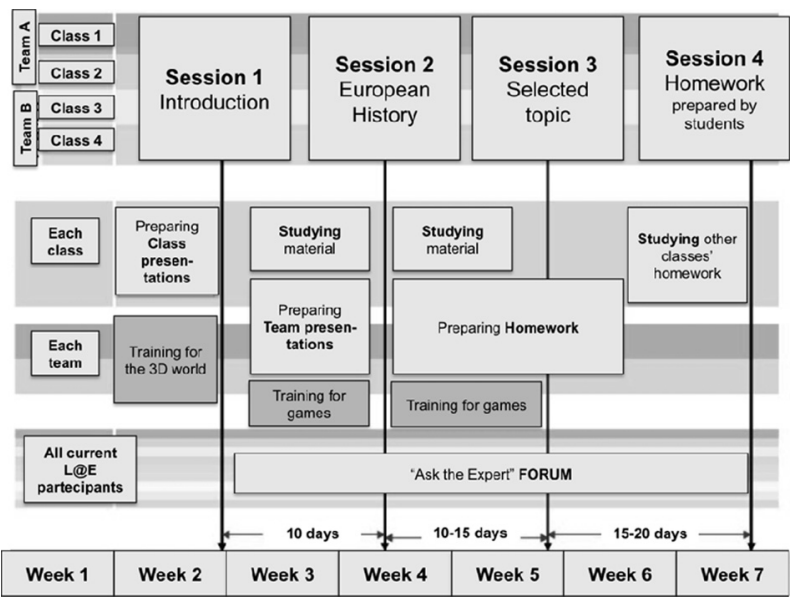

Figure 5. The L@E educational format at a glance.

ICST Transactions on e-Education and e-Learning 8 July-September 2011 | Volume 11 | Issues 7-9 | e3 
Table 2. Storyboard of the Session 1.

\begin{tabular}{|c|c|c|c|c|}
\hline Time & Environment & Activities & Content & Goals \\
\hline \multirow[t]{2}{*}{$6-8^{\prime}$} & \multirow[t]{2}{*}{ Meeting point } & Welcome & 2 boards & \multirow[t]{2}{*}{ Introduce the experience } \\
\hline & & $\begin{array}{l}\text { Introduction to the } \\
\text { world and to the experience }\end{array}$ & $\begin{array}{l}1 \text { interviewee video }+ \text { picture/video } \\
\text { of the } 3 \mathrm{D} \text { world }\end{array}$ & \\
\hline $15-20^{\prime}$ & City domes & $\begin{array}{l}\text { Class presentation } \\
\text { Jolly questions }(2 / 3)\end{array}$ & $\begin{array}{l}4 \text { presentations }+ \text { photographs } \\
\text { Jolly questions }(2 / 3)\end{array}$ & Introduce students to each other \\
\hline \multirow[t]{2}{*}{$12^{\prime}$} & \multirow[t]{2}{*}{ Play ground } & \multirow[t]{2}{*}{ Olympic games } & \multirow[t]{2}{*}{$\begin{array}{l}\text { Quick questions on auxiliary } \\
\text { materials }(4 / 5)\end{array}$} & $\begin{array}{l}\text { Get acquainted with the world } \\
\text { and some specific features }\end{array}$ \\
\hline & & & & Elect the forum manager \\
\hline $2-5^{\prime}$ & Global chat & $\begin{array}{l}\text { Goodbye, feedback, assignments } \\
\text { (lst part homework: research of } \\
\text { material evidences) }\end{array}$ & - & Contact between students \\
\hline
\end{tabular}

In Session 3 (Selected topic), a specific European issue is dealt with in depth, e.g. the role of religion or of languages in the formation of nation-states. Again, discussion and games take place. Afterwards, students still have a couple of weeks to complete their homework, researching in archives, museums, and local cultural institutions and collaborating with their team members via e-mail and on a team forum. One week before the last session, students submit their homework and read the works produced by the other schools.

Finally, in Session 4 (Homework) students present their homework, comparing their ideas and discussing with their peers. They get thoroughly involved in the discussion, passionately defending their point of view and accurately analyzing the others'; this moment is the most culturally intense of the whole experience.

\subsection{Conceptual design of the educational experience}

We have described the Session 1 in terms of the concepts previously defined using the theater metaphor. To do this we have followed the workflow shown in Table 3: the first column specifies the design phase and the step number; the second column contains the name of the involved designer's profile.

In the design workflow, first the Educational Designer or Pedagog defines the theater, the screenplay, the cameras, and in general all the aspects related to the general orchestration of the Educational Experience; then the Teacher or Domain Expert adds the design details about the educational contents to meet, defining Theater Entity Elements such as images, board contents, games' clues, etc.; and at last the Technical Expert closes the model adding the technical parameters needed to generate the virtual environment, for example he/she associates the 3D graphic files to each scene, sets the avatar speed, defines the contents' URLs, etc.

To systematically evaluate the proposed design approach we prepared a mockup tool, whose starting screen is shown in Figure 6, in order to simulate the workflow to be followed during the design process. In this case study report we provide readers with some of the most important screen shots of the authoring wizard to help readers in evaluating every design step and understanding its effectiveness.

The Session 1 of L@E started in the 'Meeting Point' space (see Table 2), where there was a virtual meeting of four classes; we considered 10 actors:

- four students for each team (A and B);

- one guide;

- one helper.

Following the workflow defined in the Table 3, in Step 1 the first element to be defined is the Theater with its map field, that has been set up to the value of 'EuropeTheater' by the Educational Designer or the Pedagog; then, in a successive step, the Technical Expert will define also the IP addresses of the server needed for content providing and shared state distribution among 3D users, filling fields in the left of the form shown in Figure 6.

In Step 2 the Scenography and the Environments where the collaborative experience takes place (Figure 7) are defined. The Educational Designer specifies the name of all scheduled environments. In this case study we consider only first session of L@E thus only one Act is modeled, which is played in three different environments:

- Meeting point;

- City domes;

- Playground.

The Domain Expert deals with the location of the environment on the Stage, then the Technical Expert specifies the URLs of the $3 \mathrm{D}$ graphic models of every environment.

In Step 3 the Educational Designer defines the Stage where the number of Acts it is made of; then he/she specifies the Scenography, the Theater Entity, the Role, the Director, and the Prompter. 
Table 3. A fragment of the design workflow followed during the case study.

\begin{tabular}{|c|c|}
\hline Static view & Designer profile \\
\hline 1. Define Theater & Educational Designer/Pedagog \\
\hline 2. Define the Scenography (Environment, Screenplay) & Educational Designer/Pedagog \\
\hline $\begin{array}{l}\text { 2.1. Placing the cameras and the lights in the } \\
\text { environments }\end{array}$ & Teacher/Domain Expert \\
\hline 3. Define the Stage and the Act number & Educational Designer/Pedagog \\
\hline 4. Define the Theater Entity & Educational Designer/Pedagog \\
\hline 4.1. Actor & Educational Designer/Pedagog \\
\hline 4.2. Element & Educational Designer/Pedagog / Teacher/Domain Expert/Technical expert \\
\hline 4.3. Curtain & Educational Designer/Pedagog/Teacher/Domain Expert/Technical expert \\
\hline 5. Define the Role and assign the Script to each role & Educational Designer/Pedagog \\
\hline 6. Define the Director & Educational Designer/Pedagog \\
\hline $\begin{array}{l}\text { 7. Define the Prompter, specifying the instructions that } \\
\text { he/she can provide to the actors during the performance }\end{array}$ & Educational Designer/Pedagog \\
\hline 8. For each Act: & Educational Designer/Pedagog \\
\hline \multicolumn{2}{|l|}{ 8.1. Define the number of scenes } \\
\hline \multicolumn{2}{|l|}{$\begin{array}{l}\text { 8.2. Associate the specific environment and Theater } \\
\text { Entities to each scene }\end{array}$} \\
\hline $\begin{array}{l}\text { 8.3. Define for each Theater Entity starting Position, } \\
\text { Rotation, and Scale }\end{array}$ & Technical expert \\
\hline Dynamic view & Designer profile \\
\hline 9. Define the start and end Time of each Act & Educational Designer/Pedagog \\
\hline 10. Define the Scene Director & Educational Designer/Pedagog \\
\hline \multicolumn{2}{|l|}{ 11. For each Scene that compose an Act, define: } \\
\hline 11.1. The start and end Time of each Scene & Educational Designer/Pedagog \\
\hline 11.2. The Scene Script & Educational Designer/Pedagog \\
\hline $\begin{array}{l}\text { 11.3. The instructions that the Stage Whisper executes } \\
\text { during the Scenes }\end{array}$ & Educational Designer/Pedagog/Technical expert \\
\hline $\begin{array}{l}\text { 11.4. The Event and the Artifact executed by the Actors } \\
\text { and created by themselves }\end{array}$ & Educational Designer/Pedagog/Technical expert \\
\hline
\end{tabular}

In Step 4 the designer adds Theater Entities (Figure 8) as Actors, Elements, and Curtains that have already been prepared by programmers, together with their characteristics both from the conceptual point of view (i.e. name, role, etc.) and from the technical point of view (i.e. avatars' position, colors, etc.).

The Actors of a L@E experience are:

- Four students of the A-team: UserAl, UserA2, UserA3, UserA4;

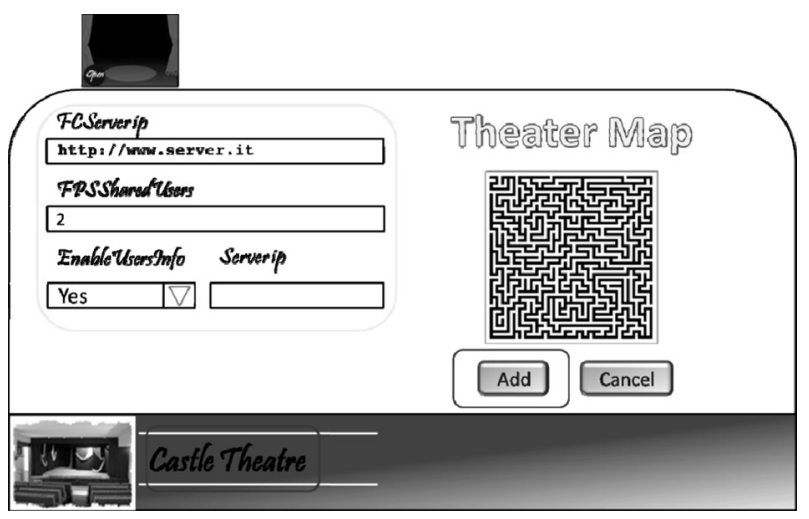

Figure 6. Step 1: Definition of the Theater map.
- Four students of the B-team: UserB1, UserB2, UserB3, UserB4;

- The Guide and the Helper.

Moreover, the Elements specified by Educational Designer to define the first environment (MeetingPoint) are:

- Boardl: Planet 3D4E (3D for Europe) Schema: a map of the $3 \mathrm{D}$ virtual world;

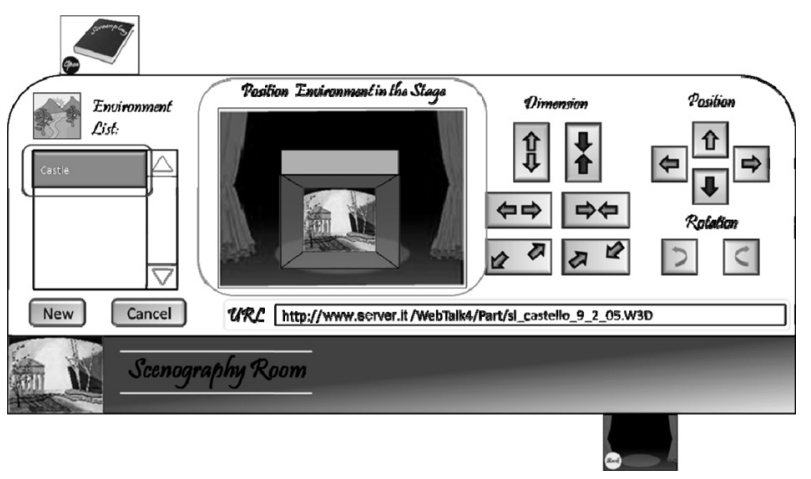

Figure 7. Step 2: Definition of the Scenography. July-September 2011 | Volume 11 | Issues 7-9 | e3 


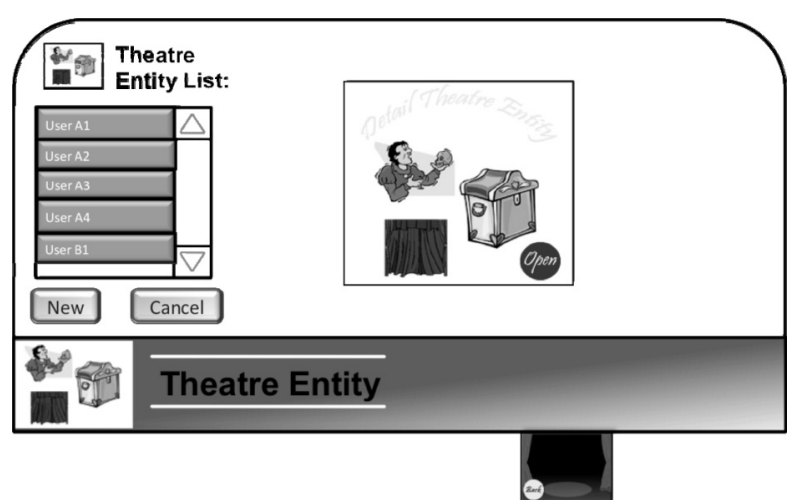

Figure 8. Step 4: Theater Entity definition.

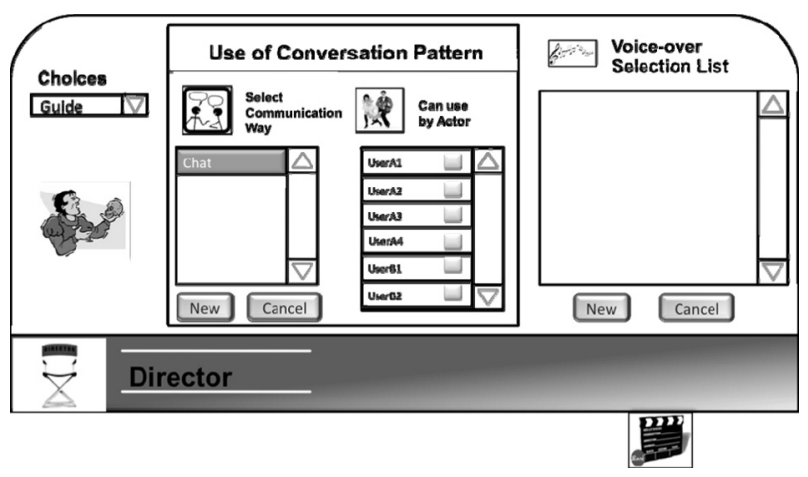

Figure 10. Step 6: Director definition.

- Board2: The four cooperative sessions representing the workflow of the activities to be performed by students (Figure 5);

- Board3: Question about a flag of a European country (Figure 19);

- Board4: Question about a Euro cent of a European country;

- Doorl: Door toward City Domes environment;

- Door2: Door toward Playground environment.

Then Domain Expert specifies all allowed actions that can be performed interacting with those Elements, for example:

- Boards open a web page when activated;

- Doors take users in another environment when activated.

Once defined the Theater Entities, the Educational Designer starts specifying Roles (Step 5 and Figure 9):

- TeamA member: two pairs of students of two different European Countries belonging to team A;

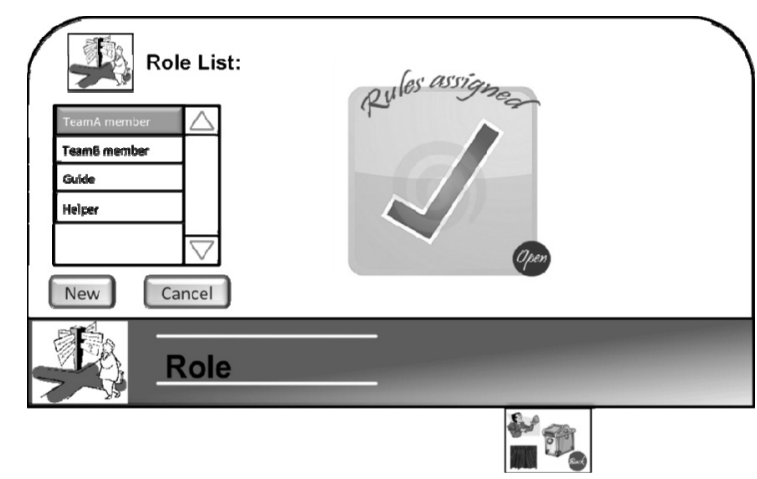

Figure 9. Step 5: Roles definition.

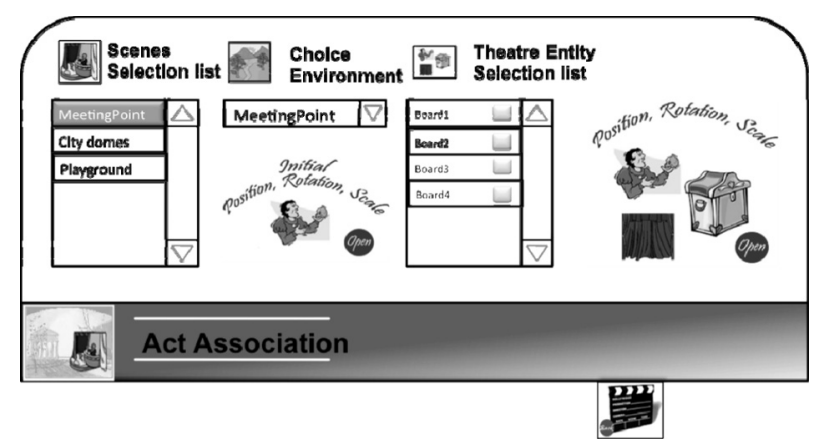

Figure 11. Step 8.1 and 8.2: Association between Acts and Theater Entities.

- TeamB member: two pairs of students of two different European Countries belonging to team B;

- Guide role: the 'educator' who has the task of directing the activities, coordinating students, assigning scores, and also penalties to teams for rude behavior;

- Helper role: the staff member who has the task of solving technical problems or making sure that no one gets lost or left behind.

Also, the Educational Designer specifies the Scripts assigned to every Role, i.e. the set of rules every Actor has to follow according to the particular context (Act, Scene, Time, occurred Event) in which he/she plays.

In Step 6 the designer defines the Director, which is played by the Guide, and activates the Conversational Pattern available in the session (Figure 10), i.e. the chat.

In a similar way, in Step 7 the Prompter, played by the Helper, is defined.

In Steps 8.1 and 8.2 the Act scenes and the corresponding Theater Entities are associated. For example, in Figure 11 the designer has modeled Board 1, Board 2, Board 3, and Board 4 as Theater Entities belonging to the Meeting Point Scene. 
In Step 8.3 the starting state of each Theater Entity (Elements, Actors, and Curtains) is defined (Figure 12). The designer specifies the position of the Stage where every Theater Element is located in, when a Session starts, and when an Actor enters the Scene. For example, in Figure 12 the designer sets up the position of the Board $l$ in the center of the Meeting Point environment; further fine positioning can be done using the 'Position' and 'Rotation' arrows.

The educational format of L@E project is thought for sessions that must last at a fixed time (according to the student schedule); for this reason, the Educational Designer must specify the time duration of each Act in terms of start time and end time. This work is done during the Step 9 (the first step of the Dynamic View); as shown in Figure 13, the designer sets the start time of Act 1 to 10:00 am and the end time to 10:45 am. Anyway the guide has the power to extend the duration of an act while it is in session in case some people are not finished, through his/her control panel.

In Step 10 the designer defines the Scene Director, i.e. the Actor who has the role of session's guide (Figure 14).

In Step 11 the configuration is finalized. In the first subtask (Step 11.1) the designer specifies the time dura-

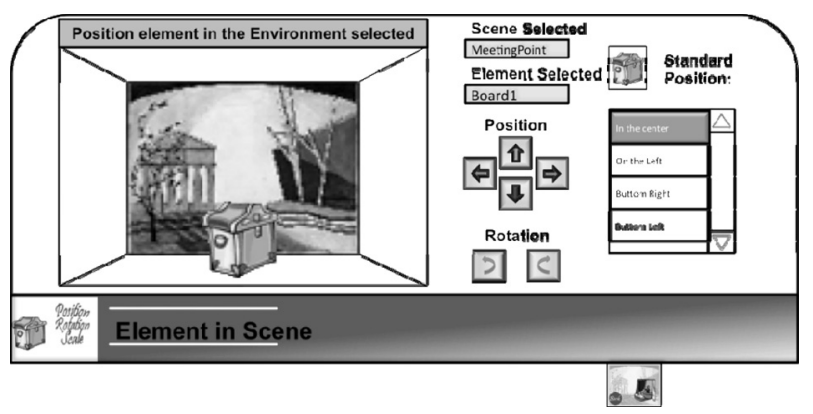

Figure 12. Step 8.3: Starting state definition.

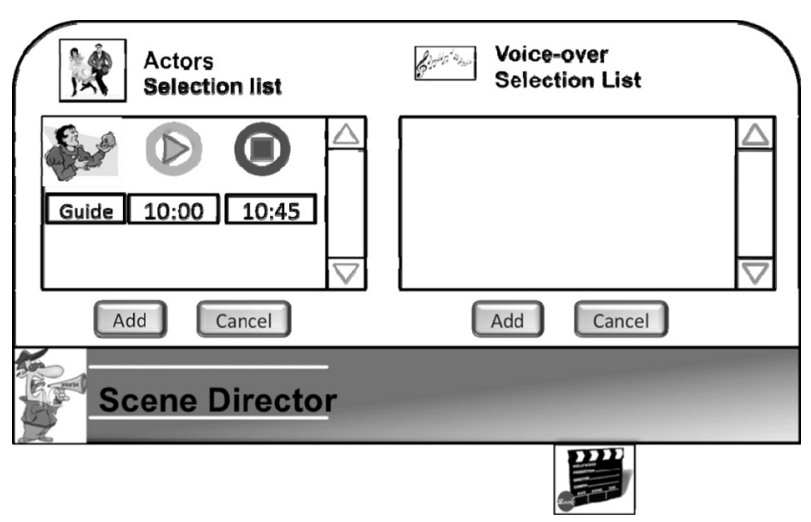

Figure 14. Step 10: Definition of the Scene Director in Act1 (L@E Session 1). tion and the sequence of Scenes. In Figure 15 the Educational Designer or Pedagog sets up the start and end times of the Scene 1 and he/she defines the 'City Domes' as next Scene to be played.

Then the Domain Expert creates the Scene Script, i.e. the Events that are associated to every Theater Entity. For example, in Figure 16 the designer defines an interaction between the Actor guide and the Board 1, specifying that the guide is allowed to open the Board 1 within the Scene 1 .

Lastly the Technical Expert finalizes configuration done by the Domain Expert in Step 11.2 providing details on behavioral logic as Events (i.e. 'Take') and Actions (i.e. 'Open') with their corresponding implementation (i.e. OnLeftClick, GoToUrl).

For example, as can be seen in Figure 17, the Domain Expert specifies that the Actor guide can take the Board 1 and this Action will Open its content in a new browser window; moreover, the Technical Expert defines that the 'Take' Event is performed whenever a left click is done on the Board 1 object and he/she specifies that a 'GoToUrl' behavior that will open a web browser window showing a content (boardl.html) is automatically performed.

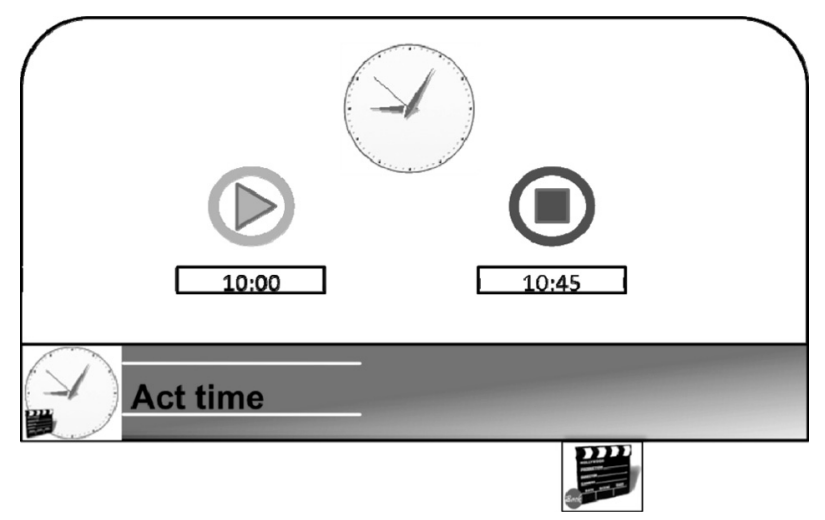

Figure 13. Step 9: Setting of the duration of the first Act.

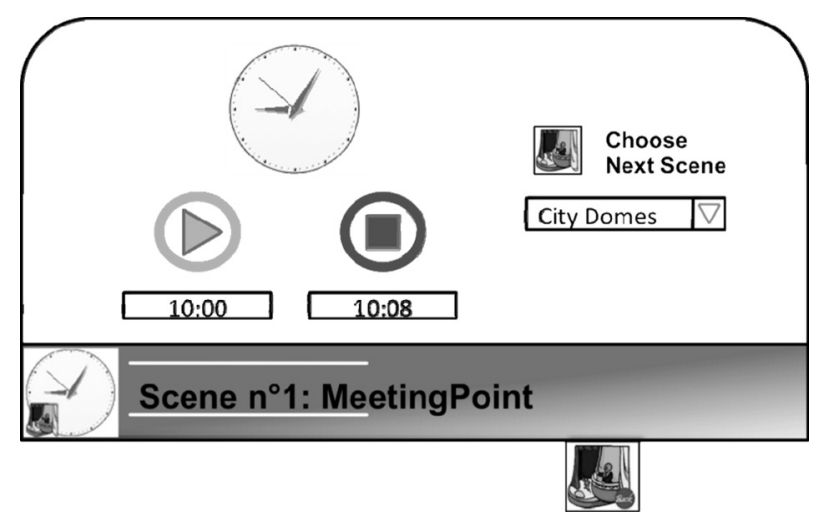

Figure 15. Step 11.1: Definition of the time duration of the first Scene (MeetingPoint). July-September 2011 | Volume 11 | Issues 7-9 | e3 


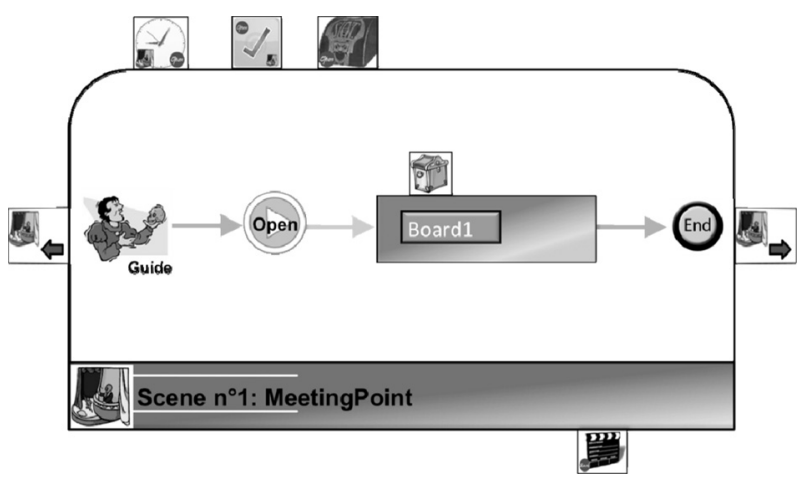

Figure 16. Step 11.2: Definition of a fragment of Scene Script; the Actor guide is allowed to open Board 1 during Scene 1.

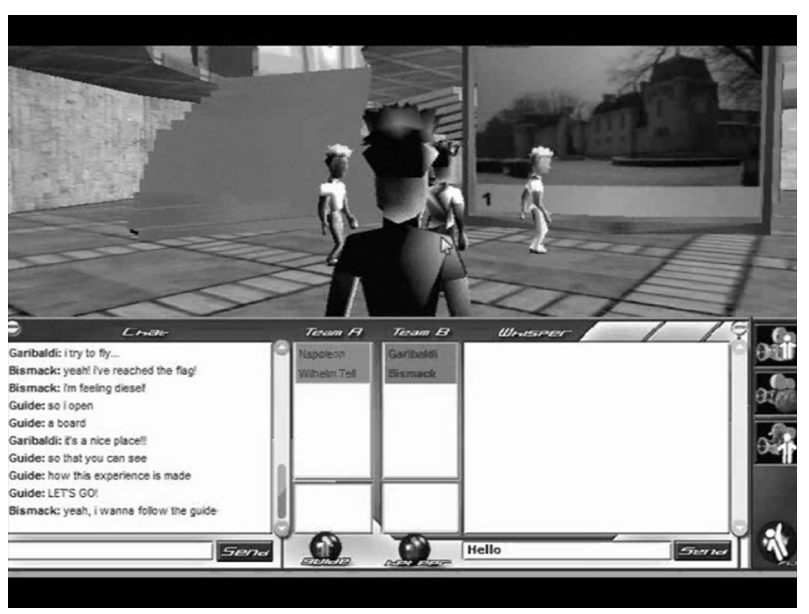

Figure 18. Avatars in front of Board 1 during the Session 1 of L@E.

For lack of space we do not describe the whole design process, anyway the affinity between the theater metaphor and the design of the virtual environment is clear: the virtual environment is defined as a theater in which the different collaborative sessions are named Act and the actors are the users participating to the specific act.

In the next paragraph we provide readers with an overview of the technical work needed to deploy the educational experience as a $3 \mathrm{D}$ virtual world.

\subsection{Deployment of the educational experience}

The deployment of a collaborative session designed through the proposed method is still hand coded. Every concept expressed exploiting the theater metaphor has to be translated (mapped) in the configuration script that is provided as input to the chosen CVE engine. In the following we provide some real examples we did configuring the WebTalk runtime engine.

Code 1 General setting of the L@E Session 1.

$<$ Configuration $>$

$<$ FCServer

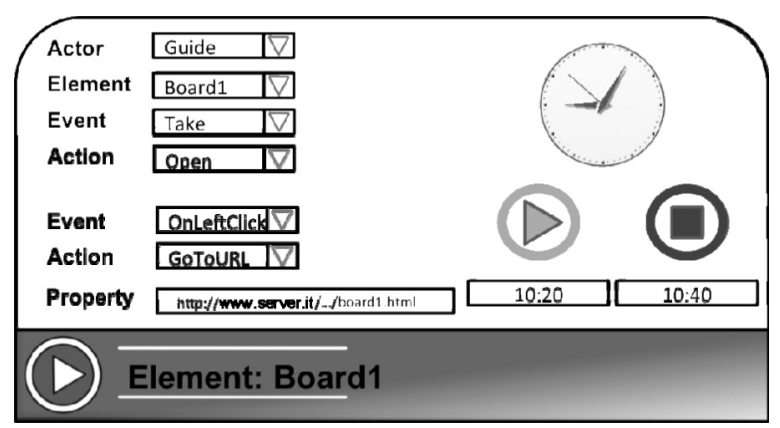

Figure 17. Step 11.4: Technical Expert defines how the abstract behavior designed in Step 11.2 is mapped to the implementation.

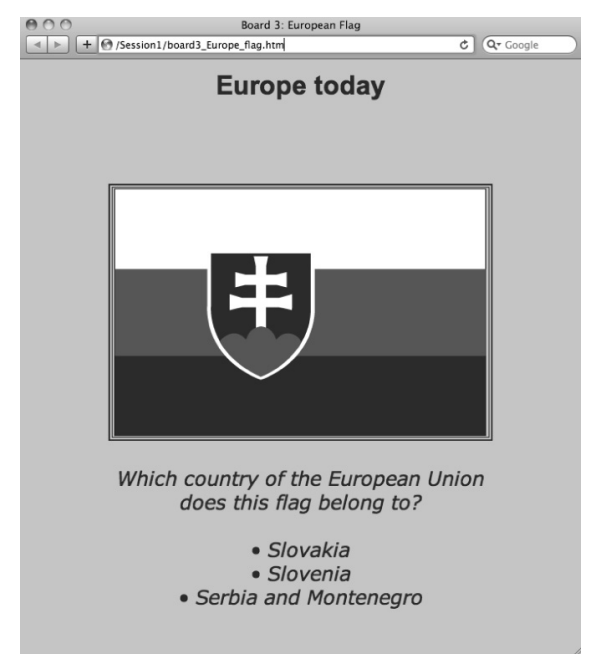

Figure 19. HTML page (board3_Europe_flag.htm) opened when the Board 1 is clicked.

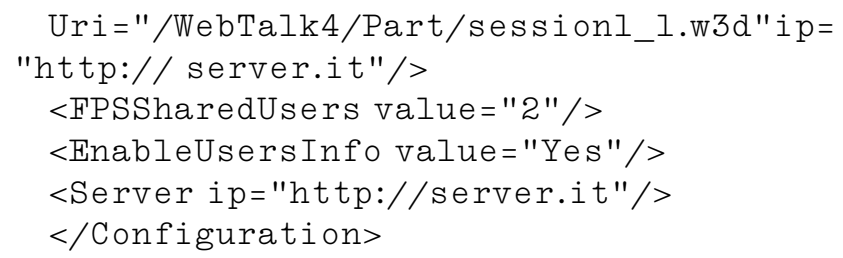

According to Figure 6, Code 1 provides the general settings of the L@E environment. A L@E session, and more in generally every WebTalk virtual world, uses two different servers: one to host the 3D objects and the session specific contents (i.e. images, boards, etc.) whose address is specified by the $<$ Server $>$ element, and another one needed to propagate among all connected clients the shared state as avatars' mutual position or actions that they perform; this second server is often called 'Collaboration Server' and its address is specified by the <FPSSharedUsers> Element. Finally, through the $<$ EnableUserInfo> element the system is requested to show the username of each user logged in the virtual environment over his/her avatar. 
Code 2 Configuration of a Board object with its geometric properties and the actions that the avatars can perform over it.

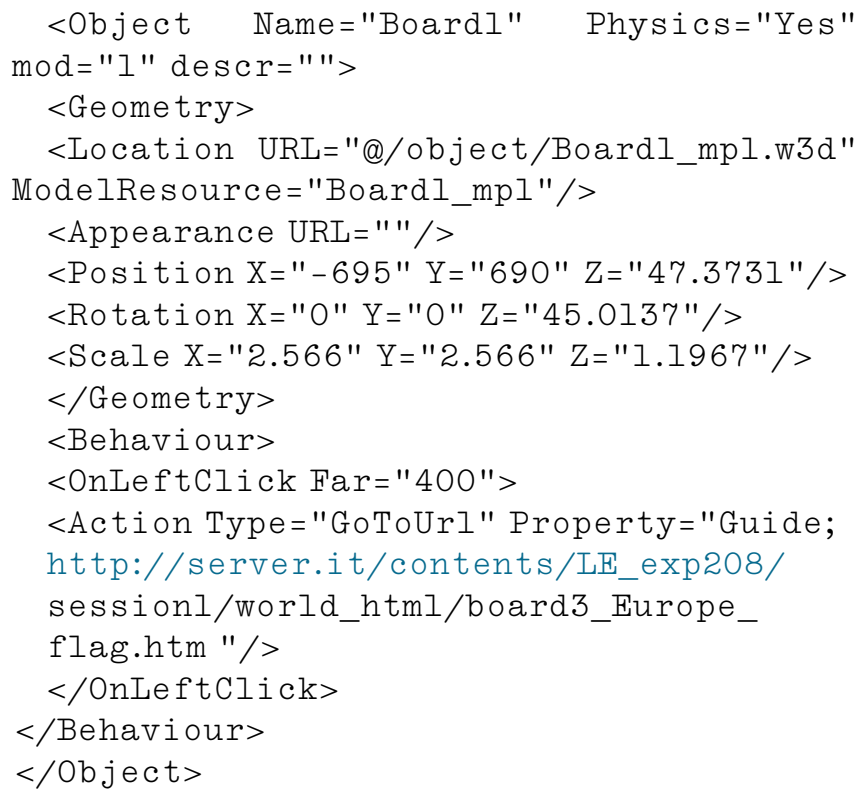

Code 2, according to Figure 17, defines the static properties of the object Board 1 (i.e. position, rotation, scale, etc.) and its dynamic behavior: when the Guide is almost near to the object (parameter Far=400) and he/she left clicks on it, the web browser will load (<Action Type $=$ "GoToUrl" $>$ ) the page at the address http:// server.it/contents/LE_exp208/sessionl/world_html/ board3_Europe_flag.htm.

Code 3 (Figure 18) configures the static properties of the Door 1 as the location of the $3 \mathrm{D}$ graphic model that is used to represent the object (element <Location>) and the position, rotation, and scale inside the world coordinates (elements <Position>, <Rotation>, and <Scale $>$ ). Moreover Code 3 (Figure 20) configures also an interaction metaphor (element <Metaphor num $=" 1 ">$ ): when the Guide (element <UserGuide>) touches (element $<$ OnProximity Distance $=" 150 ">$ ) the Door 1 (i.e. its relative distance is less that 150 units), he/she is teleported to the next 3D environment (element <Action Type="StarTrek" >, where "StarTrek" is the name

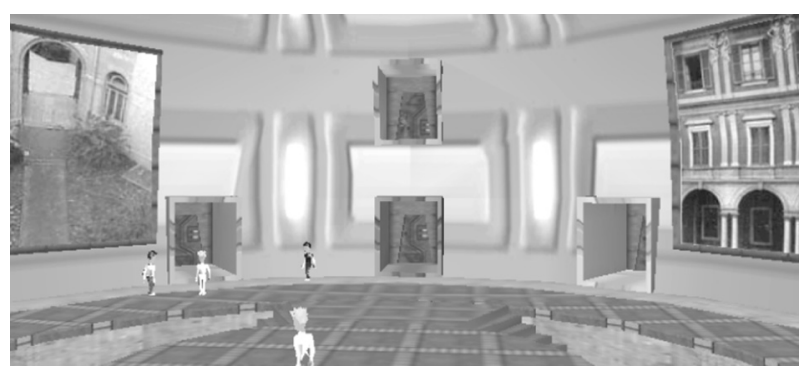

Figure 20. The white avatar (the guide) is going toward the left door, thus causing the teleport of himself in another 3D environment. developer got to the teleport behavior). An interaction metaphor represents how actions in the virtual world can evolve through explicit rules, i.e. interaction patterns among users and between users and the environment. These rules encompass various aspects, like the way users can gather in groups to talk or navigate the virtual space, or how the state of the graphic objects is visualized. A specific metaphor can be automatically activated by the environment or manually by the Guide.

Code 3 Configuration of a Door element with a teleport action that can be activated only by the user Guide.

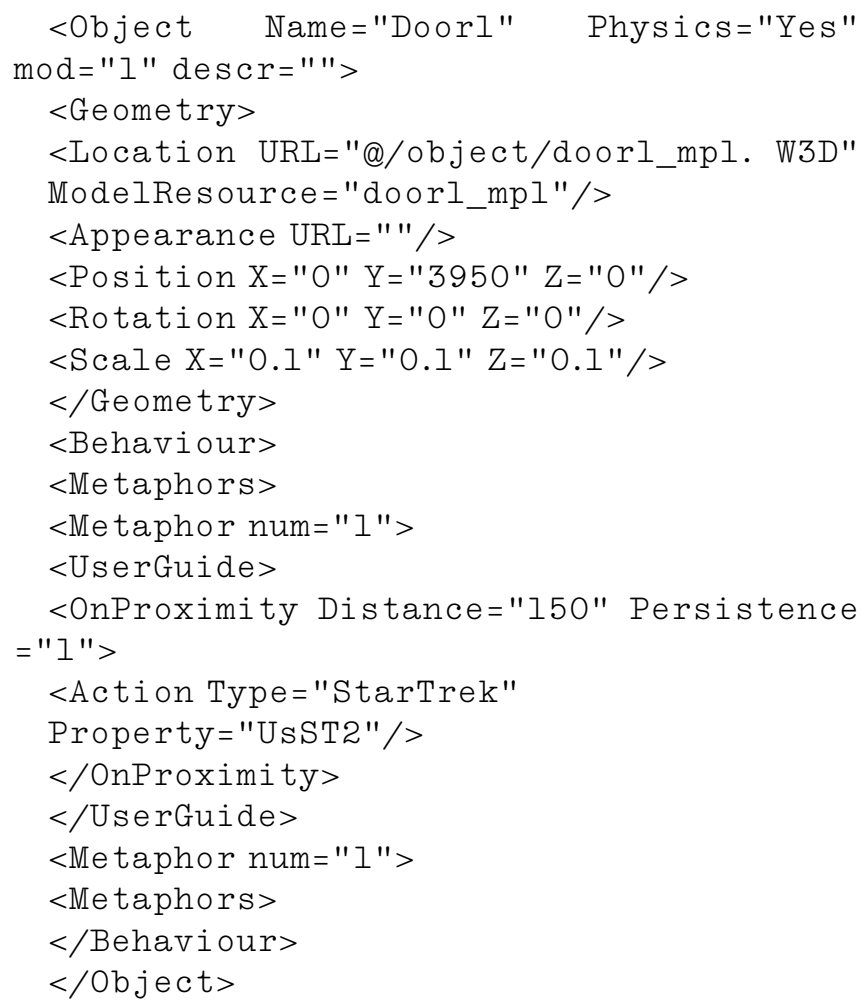

For lack of space, we do not provide other details about the implementation; anyway we are confident that the advantages of a sound and rigorous design of a collaborative virtual world are clear: the deployment can be automatically supported using mapping rules and should be model-driven.

\section{Conclusion}

The growth of CVEs for education (but also for other domains as cultural heritage, eEntertainment, eMarketing, and eMeeting) calls for new conceptual tools that enable domain experts (pedagogs and educational designers) and engineers to model and keep under control the design complexity unleashed by innovative $3 \mathrm{D}$ virtual worlds, and carefully consider the impact of the design decisions on the optimal flow of the user experience during online sessions.

To meet this challenge, in this paper we proposed a set of founding concepts that enable pedagogs, teachers, and tutors designing effective $3 \mathrm{D}$ virtual worlds for edu- 
cation. To keep simple and sound our concepts, we grounded the design method on the theater metaphor. Summarizing the approach, the following are the key artifacts:

- From our experience in developing 3D collaborative virtual worlds for education and as a result of a deep analysis of existing CVEs and file formats (VRML and X3D), we derived a map of recurring concepts in virtual worlds (Figure 1).

- We defined the design semantics of each model primitive (Table 1) exploiting the theater metaphor (Figure 2).

- We provided designers with two modeling views: the static view and the dynamic view (Table 2 ).

Comparing our contribution with the state of the art, we can affirm that new is the proposal of a conceptual method for designing CVEs, and original is the idea to apply the theater metaphor to $3 \mathrm{D}$ virtual worlds.

We demonstrated through a real case study the promising advantages of our approach: expressiveness to capture collaborative features at a high level of abstraction, semi-formality to facilitate the establishment of a common ground between designers of educational experiences and CVEs engineers, and guidance to enable non-experts to cope with all the relevant aspects of a 3D virtual world.

Future research directions will be twofold. On the one hand, we plan to define a language for the conceptual modeling of CVEs. To reach this goal we will formally define the design semantics and the design notation of each modeling primitive. In this direction, we already started two feasibility studies to compare approaches, one using an ontological approach and OWL [32] [40] to express the CVE design knowledge, and another using the OMG technology and MOF [33] [41] to specify the design meta-model. On the other hand, we plan to evolve our authoring wizard in a design tool that will be used directly by CVE designers. The tool will be based on the (OWL or MOF) meta-model; its XML-serialized output will be the input for our CVE runtime technology. Following this approach we will provide educational designers with means to fast prototype $3 \mathrm{D}$ virtual worlds for eLearning, saving them form technological details.

Acknowledgements. We thank all the people who contributed to our research: the engineers who created the different versions of our CVE technology, the educators who ran the eLearning experiences under the L@E, S@L, and L@SS programs, and the people who participated in brainstorming sessions to elicit the CVE concepts. This work is co-supported and partially funded by the Italian Ministry of Education, University and Research (MIUR) under the FIRB RBNE07RCPX L4A (Learning for All) research project, coordinated by the HOC-Lab of Politecnico di Milano.

\section{References}

[1] Benford, S., Greenhalgh, C., Rodden, T. and Pycock, J. (2001) Collaborative virtual environments. Commun. ACM 44(7): 79-85, ACM Press.

[2] Hsiao, T. and Yuan, S. (2005) Practical middleware for massively multiplayer online games. IEEE Internet Comput. 9(5): 47-54, IEEE Press.

[3] Zhou, Z., Jin, X. and Vogel, D. (2010) Individual motivations for using social virtual worlds: an exploratory investigation in second life. In 43rd Hawaii International Conference on System Sciences (HICSS2010) (Washington DC, USA: IEEE Computer Society), 1-10.

[4] McArdle, G., Monahan, T. and Bertolotto. M. (2006) $3 \mathrm{D}$ Collaborative virtual environments for e-learning and m-learning. In 5th IASTED International Conference on Web-Based Education (WBE'06) (Anaheim: ACTA Press), $1-6$.

[5] Berger, H., Dittenbach, M., Merkl, D., Bogdanovych, A., Simoff, S. and Sierra, C. (2006) Playing the e-business game in $3 \mathrm{D}$ virtual worlds. In 18th Australia Conference on Computer-Human Interaction: Design: Activities, Artefacts and Environments (OZCHI '06) (New York: ACM Press), 333-336.

[6] Hoffman, D.L. and Novak, T.P. (1996) Marketing in hypermedia computer-mediated environments: conceptual foundations. J. Marketing 60(3): 50-68, American Marketing Association.

[7] Prasolova-Forland, E., Wyeld, T.G. and Lindas, A.E. (2008) Developing virtual heritage application with 3D collaborative virtual environments and mobile devices in a multi-cultural team: experiences and challenges. In Third International Conference on Systems (ICONS 08) (Washington DC, USA: IEEE Computer Society), $108-113$

[8] Idrus, Z., Abidin, S.Z.Z., Hashim, R. and Omar, N. (2010) Awareness in networked collaborative environment: a comparative study on the usage of digital elements. In 9th WSEAS International Conference on Applications of Computer Engineering (ACE'10) (Stevens Point: World Scientific and Engineering Academy and Society (WSEAS)), 236-241.

[9] Dillenbourg, P. (1999) What do you mean by collaborative learning? In Dillenbourg, P. [ed.] CollaborativeLearning: Cognitive and Computational Approaches (Elsevier Science Pergamon), 1-19.

[10] Elliott, J., Adams, L. and Bruckman, B. (2002) No magic bullet: 3D video games in education. In International Conference of the Learning Sciences (ICLSO2), Seattle, Washington, October 2002.

[11] Ballesteros, I. (2006) Future and emerging technologies and paradigms for collaborative working environments. In 5th Collaboration@Work Experts Group Report (Information Society, European Commission), 1-28.

[12] ANG, K.H. and WANG, Q.Y. (2006): A case study of engaging primary school students in learning science by using Active Worlds. In First International Lams Conference 2006: Designing the Future of Learning (Sydney: LAMS Foundation), 5-14.

[13] Tsiatsos, T. and Konstantinidis, A. (2007): Exploitation of Croquet CVE platform for supporting collaborative 
e-learning environments. In ICL2007 Conference (Villach, Austria), 1-8.

[14] Gilroy, K. (2001) Collaborative e-Learning: The Right Approach (Cambridge, Massachusetts: The OTTER Group), http://www.eveandersson.com/arsdigita/asj/ elearning/.

[15] Bodas, D. and Rodriguez Artacho, M. (2007) Instructional theories to model educational content: a case study. In Fernández-Manjón, B., Sánchez-Pérez, J.M., GómezPulido, J.A., Vega-Rodríguez, M.A. and Bravo-RodríGuez, J. [eds.] Book Computers and Education: E-Learning, From Theory to Practice (Springer).

[16] Bouras, C., Giannaka, E. and Tsiatsos, T. (2010) Exploiting virtual environments and Web 2.0 immersive worlds to support collaborative e-learning communities. In Novel Developments in Web-Based Learning Technologies: Tools for Modern Teaching (Hershey: IGI Global publications), 20-45.

[17] Barchetti, U., Bucciero, A. and Mainetti, L. (2011) Collaborative learning through flexible web CVE: the experience of webtalk. In Teaching Through Multi-User Virtual Environments: Applying Dynamic Elements to the Modern Classroom (Hershey: IGI Global publications), 471-490.

[18] Learning@Europe web site, http://www.learningateurope. net/.

[19] Storia@Lombardia web site, http://www.storialombardia. it/.

[20] Learning@SocialSport web site, http://www.learningat socialsport.it/.

[21] Barab, S., Thomas, M., Dodge, T., Carteaux, R. and Tuzun, H. (2005) Making learning fun: Quest Atlantis, a game without guns. Educ. Technol. Res. Dev. 53(1): 86-107.

[22] Dede, C., Clarke, J., Ketelhut, D.J., Nelson, B. and Bowman C. (2005) Students' Motivation and Learning of Science in a Multi-User Virtual Environment (American Educational Research Association (AERA)).

[23] Kirner, T.G., Kirner, C., Kawamoto, A.L.S., Cantão, J., Pinto, A. and Wazlawick, R.S. (2001) Development of a collaborative virtual environment for educational applications. In Sixth International Conference on 3D Web Technology, 61-68.

[24] Portugal, R.C., Guerrero, L.A. and Fuller, D.A. (2000) DeskTOP, a system based on virtual spaces to support and to promote collaborative learning. In Third International Conference on Collaborative Virtual Environments (New York, USA: ACM), 199-200.

[25] Okada, M., Tarumi, H., Yoshimura, T. and Moriya, K. (2001) Collaborative environmental education using distributed virtual environment accessible from real and virtual worlds. ACM SIGAPP Applied Computing Review 9(1): 15-21.

[26] Prasolova-Førland, E. and Divitini, M. (2003) Collaborative virtual environments for supporting learning communities an experience of use. In 2003 International
ACM SIGGROUP Conference on Supporting Group Work, $58-67$.

[27] Johnson, A., Roussos, M., Leigh, J., Barnes, C., VasilaKIs, C. and MoHer, T. (1998) The NICE project: learning together in a virtual world. In IEEE Virtual Reality Annual International Symposium (Washington DC, USA: IEEE Computer Society), 176-183.

[28] Whyville virtual world, www.whyville.net.

[29] Scuola 3D virtual world, www.scuola3d.it.

[30] ActiveWorlds virtual world, www.activeworlds.com.

[31] Guerrero, L.A., Collazos, C.A., Pino, J.A., OchoA, S.F. and Aguilera, F. (2003) Designing collaborative virtual environments based on real spaces to promote community interaction. In First Conference on Latin American Web Congress (Washington DC, USA: IEEE Computer Society), 158.

[32] Rossi, D. and Turrini, E. (2007) Using a process modeling language for the design and implementation of process-driven applications. In International Conference on Software Engineering Advances (ICSEA 2007) (IEEE Computer Society Press), 55.

[33] Vanacken, D., De Boeck, J., Raymaekers, C. and Coninx, K. (2006) NiMMiT: a notation for modeling multimodal interaction techniques. In Proceedings of the First International Conference on Computer Graphics Theory and Applications, Setúbal, Portugal, February 25-28, 2006.

[34] Boeck, J.D., Vanacken, D., Raymaekers, C. and Coninx, K. (2007) High-level modeling of multimodal interaction techniques using NiMMiT. J. Virt. Real. Broadcast. 4(2).

[35] Di Blas, N., Poggi, C. and Torrebruno, A. (2006) Collaboration and playful competition in a 3D educational virtual world: the Learning@Europe experience. In PEARson, E. and Bohman, P. [eds.] Proceedings of World Conference on Educational Multimedia, Hypermedia and Telecommunications 2006 (Chesapeake, VA: AACE), 1191-1198.

[36] Di Blas, N., Paolini, P., Poggi, C. and Torrebruno, A. (2008) 3D worlds to learn and play: 6 years of projects with an engaging, pedagogically effective, and versatile educational format. In World Conference on E-Learning in Corporate, Government, Healthcare, and Higher Education (Chesapeake, VA: AACE), 738-745.

[37] Paolini, P. and Di Blas, N. (2006) Multi-user virtual environments for education: a european experience. In Reeves, T. and Yamashita, S. [eds.] Proceedings of World Conference on E-Learning in Corporate, Healthcare, and Higher Education 2006 (Chesapeake, VA: AACE), 13831394.

[38] Novak, J.D. (2010) Learning, creating, and using knowledge: Concept Mapas as facilitative tools in schools and corporations. J. e-Learn. Knowl. Soc. 6(3): 21-30.

[39] Encyclopedia Britannica, http://www.britannica.com.

[40] W3C (2004), Web Ontology Language Reference, http:// www.w3.org/TR/owl-ref/.

[41] Object Management Group (2002) Meta Object Facility (MOF) Specification-v.1.4. Technical Report (OMG). 